\title{
Anticancer Strategy Targeting Mitochondrial Biogenesis in Ovarian Cancer
}

\author{
1, Boyun Kim ${ }^{1,2}$, Dong Hoon Suh ${ }^{3}$ and Yong Sang Song ${ }^{1,2,4 *}$
}

${ }^{1}$ Cancer Research Institute, Seoul National University College of Medicine, Seoul 110-799, Korea

${ }^{2}$ WCU Biomodulation, Department of Agricultural Biotechnology, Seoul National University, Seoul 151-921, Korea

${ }^{3}$ Department of Obstetrics and Gynecology, Seoul National University Bundang Hospital, Seongnam, 463-707, Korea

${ }^{4}$ Department of Obstetrics and Gynecology, Seoul National University College of Medicine, Seoul 110-744, Korea

\begin{abstract}
Mitochondrial biogenesis (MtBIO) is the utmost requisite for cell's replication and survival, and it has been found to be involved in chemoresistance. The chemoresistance is the foremost obstacle in the treatment of patients with ovarian cancer. Several studies showed that modulation of MtBIO can lead to cancer cell death. Therefore targeting MtBIO in ovarian cancer could be a promising therapeutic approach possibly through overcoming the chemoresistance. Potential targets of MtBIO will be discussed focusing on ovarian cancer in this review.
\end{abstract}

Keywords: Mitochondrial biogenesis; Ovarian cancer; Therapeutic target; Chemoresistance

\section{Introduction}

Ovarian cancer is the most lethal gynecologic malignancy worldwide typically in the post-menopausal women and $5^{\text {th }}$ leading cause of death in the United States [1-3]. About $80 \%$ of women are diagnosed at the advanced-stage of disease and have poor prognosis. The 5 -year overall survival rate is $45 \%$ or below [4-6]. Despite the first complete response after the front-line platinum-based chemotherapeutic drugs $[7,8]$, approximately $25 \%$ patients suffer from relapse within 6 months who are thought, by definition, to have a chemoresistance [9-12]. Combination of platinum and other drugs might improve the survival rate [13], but is not out of the danger of additive toxicity [14].

Several genetic alterations have been observed in ovarian cancer, involving deactivation mutations in tumor suppressor genes, such as p53, BRCA1 and BRCA2, and activation mutation and/or amplification of proto-oncogenes, like c-MYC, KRAS and AKT [15]. Recent genomic analysis of The Cancer Genome Atlas reported mutations in p53 gene in $96 \%$ of 316 cases of high-grade ovarian serous carcinoma (HGOSC) [16]. Other important genetic changes affect phosphatidyinositol3-kinase (PI3K)-AKT-mammalian target of rapamycin (mTOR) cascade. The mTOR plays a central role in energy metabolism, cell growth/division through macromolecular synthesis and is found to be activated in ovarian cancer [6], which indicates a close relationship between genetic alteration and energy metabolism. It was observed that hexokinase (HK) II, the rate limiting initial enzyme in glycolysis, is overexpressed in ovarian cancer [12]. The genetic alterations and subsequent metabolic remodeling have been found to be associated with the chemoresistance [17], such as association of rictor (mTORC2 component) with resistance to cisplatin [2]. Cisplatin-induced caspase activation causing PTEN cleavage has also been reported as a potential mechanism of chemoresistance in ovarian cancer [18].

Mitochondria is a well-adapted endosymbiotic intracellular organelles, became efficient for energy production through-out the course of evolution [19]. They are critical for survival and proliferation of living organisms under aerobic conditions and produce ATP through oxidative phosphorylation (OXPHOS) [20]. Beyond the conventional function they have crucial role in certain neurodegenerative diseases and cancer [21-23]. Cellular proliferation largely depends on mitochondrial amount, governed by the process of MtBIO [20]. MtBIO is the production of daughter mitochondria usually from previously existed one through a division process of called fission, subsequent growth, and maintenance by fusion and autophagy of mitochondria (mitophagy) [24]. Currently it has been observed that MtBIO is associated with cancer chemoresistance $[25,26]$ through the modulation of associated proteins such as methylation-controlled J-protein (MCJ, also known as DNAJC15) [25,27], prohibitin 1 (PHB1) [28-30], myeloid cell leukemia sequence 1 (MCL-1) [31,32] etc. in ovarian cancer. Thus it can be speculated that MtBIO has fine-tuned association at least in part with the chemoresistance of ovarian cancer and can serve as suitable target for therapy.

\section{Metabolic Remodeling of Ovarian Cancer and its Relationship to the Chemoresistance}

\section{Important clinicopathologic and genetic alterations}

According to the Gynecologic Oncology Group and EuropeanCanadian investigators, platinum- and taxane-based chemotherapy after surgery has been considered as the effective treatment regimen against ovarian cancer [33] with $60 \%$ to $80 \%$ in overall response rate. However, among the relapsed patients response rate decreased to $15 \%$ to $35 \%$ to the same treatment regimen [34]. Different genetic alterations have been identified in ovarian cancer. HGOSC almost universally showed $p 53$ gene mutation, followed by genomic instability, DNA copy number abnormalities etc. $[16,35]$. The PI3K/AKT/mTOR pathway is one of the most important genetic alteration in ovarian cancer, mostly activated due to the mutations in PI3KCA gene. Alteration of PI3KCA also leads to mTOR phosphorylation and enhance tumor survival. Activation of PI3K pathway causes overexpression of $B A D$,

*Corresponding author: Yong Sang Song, MD, PhD, Department of Obstetrics and Gynecology, Seoul National University Hospital, Yongon-dong, Jongnogu, Seoul 110-744, Korea, Tel: +822-2072-2822; Fax: +822-762-3599; E-mail: yssong@snu.ac.kr

Received September 03, 2014; Accepted September 27, 2014; Published September 30, 2014

Citation: Uddin MH, Kim B, Suh DH, Song YS (2014) Anticancer Strategy Targeting Mitochondrial Biogenesis in Ovarian Cancer. J Cancer Sci Ther 6: 422 428. doi:10.4172/1948-5956.1000303

Copyright: @ 2014 Uddin MH, et al. This is an open-access article distributed under the terms of the Creative Commons Attribution License, which permits unrestricted use, distribution, and reproduction in any medium, provided the original author and source are credited. 
PAK1, GSK3B etc. [36]. Other alterations are observed in RB, RAS and NOTCH pathways. RB1 itself is found to be deleted or mutated. CDK inhibitor ( $p 16)$ inactivation allows the amplification of Cyclin E1 which further inhibits $R B 1$ via Cyclin D1 and Cyclin D2 genes. Deletion or mutation of NF1 activate KRAS-BRAF linked survival pathway [35]. NOTCH gene gets activated either via JAG1-2 or MAML1-3. Moreover, deregulated JAG1-NOTCH1 signaling can activate group of oncogenes, including MYC families possibly associated with ovarian cancer progression [37]. It was observed that FOXM1 transcription factor network is activated in $84 \%$ of cases [35]. Deletion mutations in $B R C A 1$ and $B R C A 2$ are also common in HGOSC. In low grade ovarian serous carcinoma, most prevalent mutations are detected in PI3KCA, $B R A F$ and KRAS genes. ARID1A is frequently mutated in clear-cell and low-grade endometrioid ovarian cancer [38]. One-third of clear cell cancers contain PIK3CA gene mutations. Mucinous type is reported to contain nearly $100 \%$ KRAS mutation and a high frequency of HER2 amplification [38]. Thus genetic changes are closely associated with clinicopathologic features of ovarian cancer patients.

\section{Metabolic remodeling in relation to genetic alterations}

Genetic alterations many of the time causes metabolic changes within a cell. Genetic alteration is presumed to be linked to the metabolic reprogramming in ovarian cancer because of the involvement of $p 53$ gene in metabolic pathways [6]. The $p 53$ is found to be involved in the regulation of cellular metabolic pathways besides its classical tumor suppressive functions, such as glycolysis, OXPHOS, and amino acid metabolism [39-43]. It also plays an important role in lipid and lipoprotein metabolism [44]. Thus it can be assumed that mutant $p 53$ could play a greater role in metabolic reprogramming. In HGOSC mutant p53 can enhance lipid anabolism through the interaction with sterol regulatory element-binding proteins and guanidinoacetate $\mathrm{N}$-methyltransferase, leading to fatty acids and cholesterol biosynthesis and the inhibition of fatty acid oxidation (FAO) [45]. PI3K signaling is one of the major regulators of glucose metabolism through the expression of glucose transporter GLUT1 by AKT $[46,47]$. AKT enhances glycolytic flux partially by the maintenance of HK [48], supports cancer cells for enhanced proliferation [12]. Glucose metabolism also can be promoted by RAS through enhancing glucose uptake [49]. AKT plays an important role in glucose transport and regulates glucose storage by GSK3 inhibition. AKT also involved in gluconeogenesis and FAO through FOXOs [50,51]. Recently its role in regulating lipid metabolism has been shown via modulation of cAMP [51].

\section{Chemoresistance associated with metabolic remodeling}

Metabolic remodeling of cancer cells makes the cells resistant to certain chemotherapeutics. One of the major chemoresistant mechanisms adopted by the cancer cells is the avoidance of apoptosis. A key event of early apoptosis is the permeabilization of outer mitochondrial membrane (OMM) which causes the release of cytochrome-c. Permiabilization can be achieved by voltage-dependent anion channel (VDAC) and mitochondrial apoptosis-induced channel (MAC) resides in the OMM, and mitochondrial permeability transition pore (MPTP) which consists of VDAC at OMM and adenine nucleotide transporter (ANT) at inner mitochondrial membrane (IMM). These pore systems rely on pro-apoptotic protein Bax, Bad for opening thus under the regulation of anti-apoptotic BCL-2 family proteins, such as BCL- $\mathrm{X}_{\mathrm{L}}$. OMM permeabilization is further achieved by the interaction of VDAC and ANT proteins. Malignant ovarian cancer cells frequently overexpress HK II, which is found to prevent tumor apoptosis through binding with VDAC or through inhibition of
VDAC-ANT interaction [6]. AKT, a metabolic regulator of glycolysis, is overexpressed in ovarian cancer and evidence suggests that it enhance OMM stability, thus inhibiting apoptotic cell death. AKT is found to inactivate caspase- 9 and induce XIAP expression. Activated AKT blocks ubiquitination of FLIP in p53 dependent manner [52], inhibits Bax oligomerization and inactivates Bad through phosphorylation. Further, AKT activation facilitates BCL- $\mathrm{X}_{\mathrm{L}}$ and $\mathrm{HK}$ II translocation to mitochondrial pore complex especially to VDAC [6]. In addition to $\mathrm{BCL}-\mathrm{X}_{\mathrm{L}}, \mathrm{MCL}-1$ is upregulated frequently in ovarian cancer and correlated with chemoresistance. CD95 expression in ovarian cancer is reported to be linked to the chemoresistance. HIF- $1 \alpha$, another important gene associated with ovarian cancer, upregulate IPA-2, MDM2 and VEGF and inhibits TRAIL induced Bax translocation on mitochondria [52].

\section{MtBIO and its Association with Chemoresistance in Ovarian Cancer}

The level of cellular energy depends on the amount of mitochondria or mitochondrial biomass, strictly controlled by MtBIO and essential for cellular proliferation [20]. MtBIO is a complicated process involving transcription of nuclear and mitochondrial DNA (mtDNA), nuclear and mitochondrial communications including protein import, mitochondrial dynamics (fission and fusion) and mitophagy [24]. Fission of depolarized mitochondria along with mitophagy balances the total mitochondrial mass in a cell. The first step of MtBIO deregulation is the mutation, either in nuclear DNA or mtDNA. Frequent mutations in mtDNA have been recently detected in ovarian cancer [53]. It is reported that ubiquinol-cytochrome $\mathrm{c}$ reductase core protein I (UQCRC1), a nuclear encoded component of mitochondrial complex III can affect mitochondrial morphology and/or physiology, and found to be overexpressed in ovarian cancer cells in experimental animals [54]. A number of studies demonstrated that MtBIO are enhanced in oncogene-transformed (HRAS) epithelial cancer cells evident by increased mitochondrial mass [55]. A mitochondrial import protein, MCJ found to overexpress in ovarian cancer cell line which is an indicative of upregulated MtBIO [25]. Few clinical studies have shown MtBIO in ovarian cancer [56]. A multicenter based case-control (1815 and 1900) study was conducted on Caucasian women with epithelial ovarian cancer (EOC) and revealed 128 single nucleotide polymorphisms (SNPs) from 22 genes/regions of mtDNA and 2,839 nuclear-encoded SNPs localized to 138 genes involved in MtBIO. Among the genes, nuclear respiratory factor 1 (NRF1), mitochondrial transcription terminator factor (MTERF), peroxisome proliferatoractivated receptor gamma coactivator 1-alpha (PPARGC1A or PGC$1 \alpha)$, estrogen-related receptor alpha $(E R R \alpha)$ and calcium/calmodulindependent protein kinase type II delta $(C A M K 2 D)$ found to be strongly associated with EOC risk [57]. Liu et al. found $60 \%$ somatic mutations from 10 ovarian carcinoma patients, mostly $\mathrm{T} \rightarrow \mathrm{C}$ or $\mathrm{G} \rightarrow \mathrm{A}$ transitions, restricted in the D-loop, 12S rRNA, 16S rRNA, and cytochrome-b region of mitochondrial genome [58]. The expression of mitochondrial transcription factor A (TFAM) was evaluated clinically on 60 patient's tissue samples with serous ovarian cancer. Immunohistochemical analysis revealed $56.7 \%$ positivity, and univariate survival analysis showed significantly worse overall 5-year survival rate for TFAMpositive cancer patients [59].

\section{MtBIO and metabolism}

MtBIO can influence metabolic remodeling of cancer cells through a number of ways, such as, production of different metabolites, generation of reactive oxygen species (ROS), stabilization of hypoxia 
inducible factors (HIFs), calcium ion flux etc. Mitochondria produce ROS from superoxide $\left(\mathrm{O}_{2}-\bullet\right)$ at about eight different sites on its membrane in response to different cellular stress, and upon oncogenictransformation through a variety of means, such as deregulated electron transport, less scavenging of ROS or altered mitochondrial dynamics $[60,61]$. Oxygen is critical for the survival of aerobic organisms. Enhanced ROS help cancer cells to adapt in low oxygen level or hypoxia $\left(0.3-3 \% \mathrm{O}_{2}\right.$ ). The HIF family (HIF-1 and HIF-2) can initiate the production of glycolytic enzymes to maintain ATP levels [61], thus regulate energy metabolism of cancer cells [60]. MtBIO and metabolism in malignant cells intimately related to "Warburg/reverse Warburg effect" $[62,63]$. Dysfunctional mitochondria which was the major explanation by Otto Warburg in cancer cells for enhanced aerobic glycolysis lacks sufficient evidence [64] and recently investigation by independent researchers leading to two possible explanations, glycolytic dysregulation and cancer-stromal cells metabolic coupling $[65,66]$. Glycolytic dysregulation not necessarily involve mitochondria, on the other hand, cancer-stromal cells metabolic coupling has shown that "Warburg effect" takes place in the stromal cells not in cancer cells. Cancer cells utilize the nutrient from adjacent stromal cells and maintain MtBIO for its energy needs, known as reverse Warburg effect [67].

\section{Chemoresistance associated with MtBIO}

The connection between chemoresistance and MtBIO recently has been established in ovarian cancer $[25,26]$ and it has been shown that mitochondrial networks of chemoresistant cells are well distributed throughout the cells as compared to chemosensitive ones [68]. An important step in MtBIO is the mitochondrial import of cytosolsynthesized proteins. A mitochondrial import regulatory protein $\mathrm{MCJ}$, is recently found to be involved in the development of chemoresistance in ovarian cancer [25] through its reduced expression [27]. Nuclearmitochondrial communication is necessary for the regulation of MtBIO [24]. Prohibitin (PHB), a conserved protein containing PHB domain, has been shown to regulate MtBIO [29], by regulating nuclear-mitochondrial communications [30]. It has been observed that prohibitin 1 (PHB-1) overexpression is related to chemoresistance in ovarian cancer [28]. MCL-1 is a member of the BCL-2 family proteins, involved in mitochondrial protein synthesis, apoptosis and autophagy. Of the different members of BCL-2, MCL- 1 is commonly amplified in human tumors, including ovarian cancer, and is associated with the relapse and chemoresistance [31,32]. Taken together, it can be considered that there is a strong relationship between chemoresistance and MtBIO in ovarian cancer. Therefore, the several pathways related to MtBIO could be the plausible targets for overcoming chemoresistance in ovarian cancer.

\section{Anti-Cancer Strategy Targeting MtBIO}

There are evidences that ovarian cancer cells maintain intact OXPHOS competent on mitochondria with functional TCA cycle for their survival in terms of membrane potential, ATP biosynthesis and oxygen consumption [30] even though their mitochondria might contain mutated DNA and accumulate different harmful products, such as ROS. Cancer cells in ovarian cancer can protect themselves through the maintenance of well distributed mitochondrial biomass and, MtBIO makes cancer cells resistant to chemotherapeutics and is considered as an emerging mechanism of chemoresistance. Mitochondria are required for the survival of organisms living under the aerobic environment. Thus MtBIO is supposed to be the ideal target for fast growing cancer cells. Here we show a number of molecules regulating MtBIO summarized in Table 1 , which can be considered as useful anticancer targets in ovarian cancer (Figure 1).

\section{Mitochondrial transcription factor A (TFAM)}

TFAM (also known as mtTFA) is a nuclear encoded $25 \mathrm{kDa}$ protein member of the high mobility group (HMG) box protein family and a key regulator of MtBIO. Upon import to mitochondria it performs multiple regulatory functions including mtDNA transcription, maintenance of mtDNA looping, coating and packaging (mitochondrial nucleoids) $[59,69,70]$. It contains facets for binding nuclear respiratory factor (NRF) 1 and NRF2 which act on the promoter of D-loop region leading to increased mtDNA copy number [71]. Significant overexpression of TFAM was observed in human serous ovarian cancer in association with poor 5-years survival. TFAM also works through binding with its downstream target BCL- $\mathrm{X}_{\mathrm{L}}$. The study has proposed TFAM as a noble therapeutic target for ovarian cancer [59]. Beside ovarian cancer, TFAM upregulation is also observed in breast, colorectal, bladder, endometrial and arsenic induced skin cancer with subsequent increase in MtBIO and cellular proliferation. Many study show similar results both in experimental and clinical settings [71-77]. Such findings suggest TFAM as one of the most important therapeutic targets in chemoresistant ovarian cancer.

\begin{tabular}{|c|c|c|c|c|}
\hline Protein family/type & $\begin{array}{l}\text { Targeting } \\
\text { molecules }\end{array}$ & Function & Study samples & References \\
\hline High mobility group (HMG) box protein & TFAM & $\begin{array}{l}\text { mtDNA transcription, maintenance, coating and } \\
\text { packaging }\end{array}$ & $\begin{array}{l}\text { Human Cell lines and tissue } \\
\text { samples }\end{array}$ & {$[59,69,70]$} \\
\hline $\begin{array}{l}\text { Stomatin/prohibitin/flotillin/HflK/C } \\
\text { (SPFH) domain containing protein }\end{array}$ & PHB-1 & $\begin{array}{l}\text { Express in mitochondria, nucleus, cytosol and maintain } \\
\text { communication among them }\end{array}$ & $\begin{array}{l}\text { Human Cell lines and tissue } \\
\text { samples }\end{array}$ & {$[28,78-80,95]$} \\
\hline $\begin{array}{l}\text { Anti-apoptotic B-cell lymphoma } 2 \text { (BCL- } \\
\text { 2) family protein }\end{array}$ & MCL-1 & Optic atrophy 1 (OPA-1) mediated mitochondrial fusion & Human Cell lines & {$[81-84,86]$} \\
\hline A member of the Bcl-2 family & BNIP3 & $\begin{array}{l}\text { Induction of cell death through mitochondrial } \\
\text { dysfunction in response to hypoxia inducible factor-1 } \\
\text { (HIF-1) }\end{array}$ & Human Cell lines & [89-91] \\
\hline $\begin{array}{l}\text { Mitochondrial methylation-controlled } \\
\text { protein }\end{array}$ & MCJ & $\begin{array}{l}\text { Involved in mitochondrial import and regulation of } \\
\text { mitochondrial permeability transition pore (MPTP) } \\
\text { complex }\end{array}$ & Human Cell lines & {$[25,27,87,88]$} \\
\hline Dynamin-related protein & DRP-1 & $\begin{array}{l}\text { Important key fission protein involved in mitochondrial } \\
\text { dynamics }\end{array}$ & Human Cell lines and in vivo in mice & [26] \\
\hline Nuclear respiratory factor & NRF-1 & Transcription of TFAM & $\begin{array}{l}\text { Multicenter case-control study with } \\
\text { Caucasian EOC patients }\end{array}$ & {$[57]$} \\
\hline $\begin{array}{l}\text { Peroxisome proliferator-activated } \\
\text { receptor gamma coactivator }\end{array}$ & PGC-1a & $\begin{array}{l}\text { Transcription of essential factors for mitochondrial } \\
\text { biogenesis including NRF1 and NRF2 }\end{array}$ & $\begin{array}{l}\text { Multicenter case-control study with } \\
\text { Caucasian EOC patients }\end{array}$ & {$[57]$} \\
\hline
\end{tabular}

Table 1: Possible anticancer targets involved in MtBIO in ovarian cancer. 


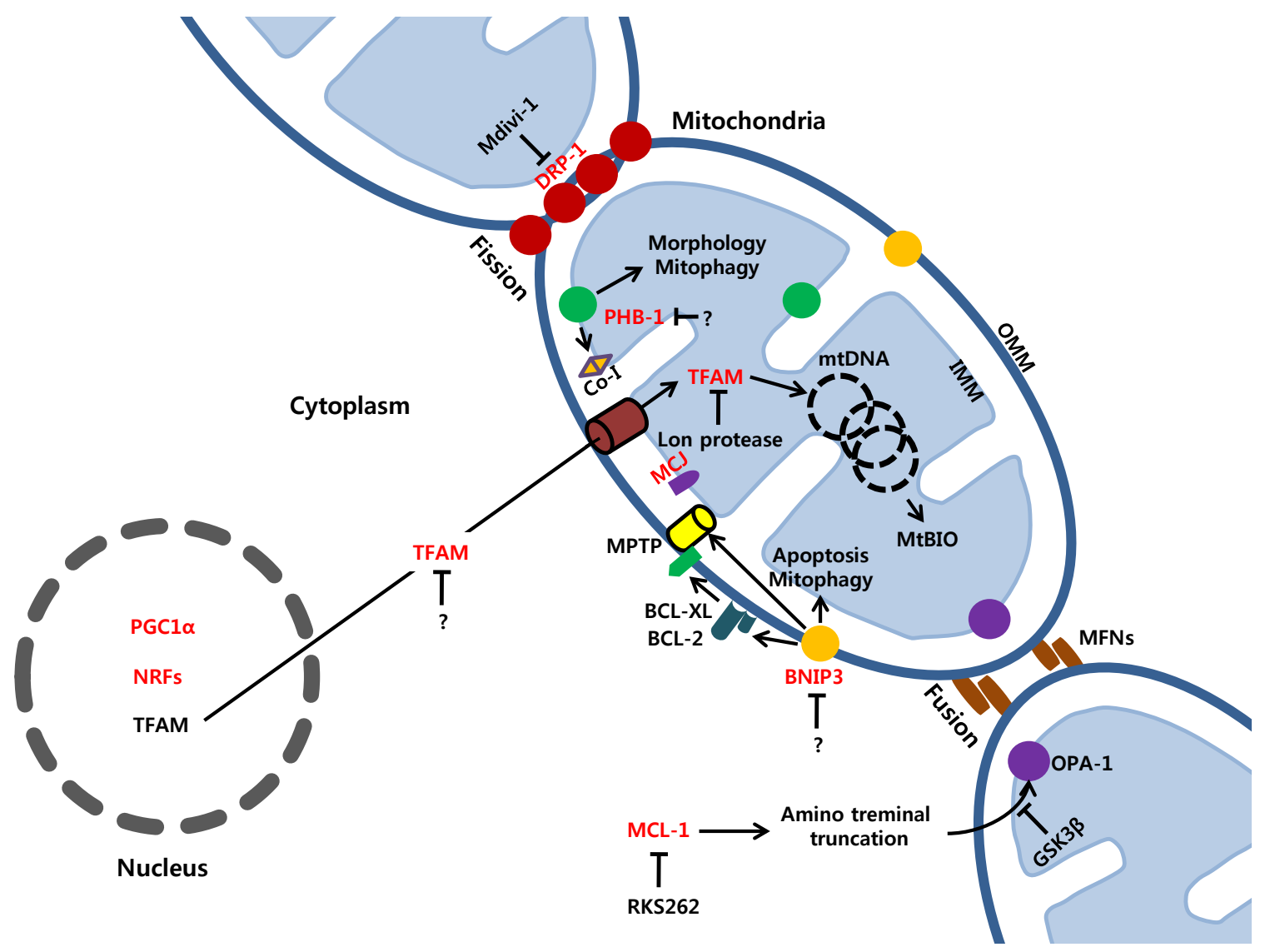

Figure 1: Targeting molecules related to MtBIO in ovarian cancer to overcome chemoresistance. Important targets are shown in red color. Major regulator of MtBIO, TFAM, synthesized mostly in the nucleus and transported to the mitochondria, where it controls mtDNA replication, maintains coating and packaging of mtDNA. It plays central role for the production of transcripts from different promoters of mitochondrial genome and augments MtBIO. In mitochondrial matrix it is degraded by Lon proteases if not bind with mtDNA. PHB-1 largely controls mitochondrial morphology thus playing a role in structural regulation. It also regulates assembly of respiratory complex 1 and subunits of cytochrome c oxidase and affects mitophagy. MCL-1 takes part in mitochondrial fusion process through the regulation of OPA-1 after amino terminal truncation. MCL-1 may degrade by GSK3 $\beta$ in mitochondrial matrix and can be inhibited in the cytosol using inhibitor (eg. RKS262). MCJ control the regulation of mitochondrial import of essential proteins and transcription factors. BNIP3 plays important roles both in apoptosis and mitophagy through the regulation of BCL-2, BCL-X and mitochondrial permeability transition pore (MPTP) etc. DRP-1 cause fragmentation of mitochondria through the process of fission. Impairment of DRP-1 activity through inhibitor mitochondrial division inhibitor (MDIVI-1) can disrupt the maintenance of MtBIO. Another master regulator of MtBIO, PGC-1a, and its downstream target NRF-1 also can be targets in ovarian cancer. OMM, outer mitochondrial membrane; IMM, inner mitochondrial membrane; Co-I, Respiratory complex 1; MFNs, mitofusin proteins; OPA-1, optic atrophy 1.

\section{Prohibitin 1(PHB-1)}

Prohibitin belongs to a conserved protein family, which contain a prohibitin $(\mathrm{PHB})$ domain more specifically, stomatin/prohibitin/ flotillin/HflK/C (SPFH) domain, observed in a diverse group of organisms from prokaryote to human [28]. It is expressed ubiquitously in different compartments of the cell such as mitochondria, nucleus and cytosol, and shuttled among them. PHB-1 has been found to be involved in chemoresistance in ovarian cancer cells and primarily associated with mitochondria. It is overexpressed in papillary serous ovarian carcinoma as well as endometrioid ovarian adenocarcinoma. This highly conserved protein can regulate cell cycle at G0/G1 phase and also confer cell survival [78]. In mitochondria, PHB-1 regulates assembly of respiratory complex 1 and subunits of cytochrome $c$ oxidase; in addition, it affects mitophagy. Inactivation of PHB-1 function can cause defects in mitochondria respiratory chain and morphological deformation of mitochondria $[79,80]$. Targeting PHB1 in ovarian cancer might lead to a promising outcome in ovarian cancer therapy.

\section{Myeloid cell leukemia sequence 1 (MCL-1)}

MCL-1 is an anti-apoptotic BCL-2 family protein [81] and its continuous transcription is required for the inhibition of apoptosis [82]. Chemoresistant A2780 cells were found to express about 8 fold higher level of MCL-1 than parental [83] and its downregulation by another member of BCL-2 family protein called PUMA ( $\mathrm{p} 53$ upregulated modulator of apoptosis) was found to chemosensitize ovarian cancer cells (A2780 and SKOV-3) [81]. Suppression of MCL1 by a potent anti-cancer agent RKS262 was found to enhance cell death in ovarian cancer cell line, OVCAR-3 [84]. It is evident from recent researches that BCL-2 family plays an important role in the regulation of fission-fusion dynamics of mitochondria through ionic homeostasis and autophagy. As a member of BCL-2 family, MCL-1 plays a noble role in mitochondrial dynamics. To perform such task it needs to be truncated at amino terminal and to be transported in to the mitochondrial matrix. Once in matrix it regulates mitochondrial fusion perhaps in conjunction with optic atrophy 1 (OPA-1) [85] It was observed that inhibition of MCL-1 causes reduction of OPA1 activity, which leads to the impairment of mitochondrial fusion, in 
turn mitochondrial fragmentation increases. Such fragmentation was rapid and independent of dynamin-related protein-1 (DRP-1) without significant ATP depletion and alteration of mitochondrial complexes (I-V) [31]. In mitochondrial matrix, MCL-1 can be degraded by GSK3 $\beta$ [86]. MCL-1 can serve as another target to restrict MtBIO for overcoming the chemoresistance in ovarian cancer.

\section{Mitochondrial methylation-controlled J protein (MCJ)}

Mitochondrial MCJ protein is associated with the import of cytosolic proteins to mitochondria and its transcriptional silencing due to hypermethylation has been associated with increased chemoresistance in ovarian cancer. Normal ovarian epithelial cells express MCJ, while it showed no or low level of expression both in primary ovarian tumors and ovarian carcinoma cell lines [87,88]. The MCJ reside in IMM and involved in the regulation of MPTP complex both in normal and cancer cells [27]. It has been found that MCJ interacts with translocase of the inner membrane 23 (TIM23) core proteins for the import of different proteins and transcription factors in to the mitochondria [25]. When MCJ is overexpressed, it can import more mitochondrial proteins or may lead to the opening of MPTP thus initiating the release of apoptotic factors [27]. As MCJ perform two different tasks, it can be conceptualized that cancer cells tightly regulate such balance for its survival and its activation might be an effective anticancer approach.

\section{Bcl-2/adenovirus E1B Nineteen Kilodalton Interacting Protein (BNIP3)}

BNIP3 is another member of the Bcl-2 family and found to be overexpressed in the hypoxic zone of many tumors, including breast cancer, glioma and ovarian cancer $[89,90]$. It is expressed on OMM and involved in mitochondrial fission and mitophagy, thus reducing total mitochondrial biomass [91]. The other function of BNIP3 is to induce cell death through mitochondrial dysfunction in response to HIF-1. However, when its transmembrane domain is lost or truncated, it failed to perform the above task. It has been observed that in ovarian cancer cells such kind of truncated BNIP3 with the loss of transmembrane domain is overexpressed [89]. Involvement of intact BNIP3 in the regulation of mitochondrial biomass is critical for cancer cells death, thus BNIP3 can be a suitable molecular target for ovarian cancer.

\section{Other Targets}

In ovarian cancer, besides the above mentioned molecules targeting MtBIO, there are other possible ones, such as DRP1 [26], NRF1, MTERF, PPARGC1A, ESRRA, CAMK2D and UQCRC1 [57]. DRP1 is the important key fission protein involved in mitochondrial dynamics. It has been observed that increase of mitochondrial fission was induced by increasing activity of DRP-1 in in vitro and in vivo in ovarian cancer. Inhibition of DRP-1 using mitochondrial division inhibitor (MDIVI-1) can reduce fragmentation of mitochondria, resulting reduced cellular proliferation [26]. ERRa was frequently over-expressed in advancedstage ovarian cancer and has been implicated as a prognostic marker recently [92-95]. Further research is necessary to determine the most appropriate target of MtBIO to combat against the chemoresistant ovarian cancer.

\section{Summary and Future Prospects}

Mitochondria play dual role in cell survival and cell death and thus serve as critical organelles of eukaryotes. Extensive studies revealed highly dynamic behavior of mitochondria and opened up many facets of research recently, as well as, the possibility of finding noble targets in cancer resistance. Resistance to anti-cancer drugs achieved through the adaptive evolution of malignant cells towards major signaling pathways usually at the upstream of MtBIO. Complete inhibition or overexpression of upstream signaling molecules largely affect cells and induce cytotoxicity even in normal cells. Directly targeting MtBIO may hit the "Achilles' heel" of cancer cells and may serve as a keen approach to exploit the loopholes of chemoresistance. In depth understanding of the key differences between normal and malignant cell's MtBIO in the future will help to design anti-cancer agents for highly specific targets.

\section{Acknowledgement}

This research was supported by the Priority Research Centers Program (2009-0093820), Basic Science Research Program (2011-0025394), and BK21 plus program through the National Research Foundation (NRF) funded by the Ministry of Education of Korea (5256-20140100).

\section{References}

1. Jemal A, Siegel R, Xu J, Ward E (2010) Cancer statistics, 2010. CA Cancer J Clin 60: 277-300.

2. Im-aram A, Farrand L, Bae SM, Song G, Song YS, et al. (2013) The mTORC2 component rictor contributes to cisplatin resistance in human ovarian cancer cells. PLoS One 8: e75455.

3. Jayson GC, Kohn EC, Kitchener HC, Ledermann JA (2014) Ovarian cancer. Lancet.

4. Classe JM, Fontanelli R, Bischof-Delaloye A, Chatal JF (2004) Ovarian cancer management. Practice guidelines for nuclear physicians. Q J Nucl Med Mol Imaging 48: 143-149.

5. Ozols RF (2002) Update on the management of ovarian cancer. Cancer J 8 Suppl 1: S22-30.

6. Suh DH, Kim MK, No JH, Chung HH, Song YS (2011) Metabolic approaches to overcoming chemoresistance in ovarian cancer. Ann N Y Acad Sci 1229 $53-60$

7. Alkema NG, Tomar T, van der Zee AG, Everts M, Meersma GJ, et al. (2014) Checkpoint kinase 2 (Chk2) supports sensitivity to platinum-based treatment in high grade serous ovarian cancer. Gynecol Oncol 133: 591-598.

8. Yang X, Fraser M, Abedini MR, Bai T, Tsang BK (2008) Regulation of apoptosis-inducing factor-mediated, cisplatin-induced apoptosis by $\mathrm{Akt}$. $\mathrm{Br} \mathrm{J}$ Cancer 98: 803-808.

9. Bao S, Wu Q, McLendon RE, Hao Y, Shi Q, et al. (2006) Glioma stem cells promote radioresistance by preferential activation of the DNA damage response. Nature 444: 756-760.

10. Kajiyama H, Mizuno M, Shibata K, Kawai M, Nagasaka T, et al. (2014) Extremely poor postrecurrence oncological outcome for patients with recurrent mucinous ovarian cancer. Int J Clin Oncol 19: 121-126.

11. Ozols RF (2002) Recurrent ovarian cancer: evidence-based treatment. J Clin Oncol 20: 1161-1163.

12. Suh DH, Kim MA, Kim H, Kim MK, Kim HS, et al. (2014) Association of overexpression of hexokinase II with chemoresistance in epithelial ovarian cancer. Clin Exp Med 14: 345-353.

13. Raja FA, Counsell N, Colombo N, Pfisterer J, du Bois A, et al. (2013) Platinum versus platinum-combination chemotherapy in platinum-sensitive recurrent ovarian cancer: a meta-analysis using individual patient data. Ann Oncol 24 3028-3034.

14. Mäenpää JU (2003) Docetaxel: promising and novel combinations in ovarian cancer. Br J Cancer 89 Suppl 3: S29-34.

15. Song YC, Kim SH, Juhnn YS, Song YS (2007) Apoptotic effect of celecoxib dependent upon p53 status in human ovarian cancer cells. Ann N Y Acad Sci 1095: 26-34

16. Wong KK, Izaguirre DI, Kwan SY, King ER, Deavers MT, et al. (2013) Poor survival with wild-type TP53 ovarian cancer? Gynecol Oncol 130: 565-569.

17. Kim SH, Juhnn YS, Song YS (2007) Akt involvement in paclitaxel chemoresistance of human ovarian cancer cells. Ann N Y Acad Sci 1095: 8289.

18. Singh M, Chaudhry P, Fabi F, Asselin E (2013) Cisplatin-induced caspase 
Citation: Uddin MH, Kim B, Suh DH, Song YS (2014) Anticancer Strategy Targeting Mitochondrial Biogenesis in Ovarian Cancer. J Cancer Sci Ther 6: 422-428. doi:10.4172/1948-5956.1000303

activation mediates PTEN cleavage in ovarian cancer cells: a potentia mechanism of chemoresistance. BMC Cancer 13: 233.

19. Davila AF, Zamorano P (2013) Mitochondria and the evolutionary roots of cancer. Phys Biol 10: 026008.

20. Yoboue ED, Mougeolle A, Kaiser L, Averet N, Rigoulet M, et al. (2014) The role of mitochondrial biogenesis and ROS in the control of energy supply in proliferating cells. Biochim Biophys Acta 1837: 1093-1098.

21. Itoh K, Nakamura K, lijima M, Sesaki H (2013) Mitochondrial dynamics in neurodegeneration. Trends Cell Biol 23: 64-71.

22. Johri A, Beal MF (2012) Mitochondrial dysfunction in neurodegenerative diseases. J Pharmacol Exp Ther 342: 619-630.

23. de Moura MB, dos Santos LS, Van Houten B (2010) Mitochondrial dysfunction in neurodegenerative diseases and cancer. Environ Mol Mutagen 51: 391-405.

24. Diaz F, Moraes CT (2008) Mitochondrial biogenesis and turnover. Cell Calcium 44: 24-35.

25. Schusdziarra C, Blamowska M, Azem A, Hell K (2013) Methylation-controlled $\mathrm{J}$-protein MCJ acts in the import of proteins into human mitochondria. Hum Mol Genet 22: 1348-1357.

26. Farrand L, Byun S, Kim JY, Im-Aram A, Lee J, et al. (2013) Piceatanno enhances cisplatin sensitivity in ovarian cancer via modulation of p53, X-linked inhibitor of apoptosis protein (XIAP), and mitochondrial fission. J Biol Chem 288: 23740-23750.

27. Sinha D, D'Silva $P(2014)$ Chaperoning mitochondrial permeability transition: regulation of transition pore complex by a J-protein, DnaJC15. Cell Death Dis 5: e1101.

28. Gregory-Bass RC, Olatinwo M, Xu W, Matthews R, Stiles JK, et al. (2008) Prohibitin silencing reverses stabilization of mitochondrial integrity and chemoresistance in ovarian cancer cells by increasing their sensitivity to apoptosis. Int J Cancer 122: 1923-1930.

29. Ahn CS, Lee JH, Reum Hwang A, Kim WT, Pai HS (2006) Prohibitin is involved in mitochondrial biogenesis in plants. Plant J 46: 658-667.

30. Sripathi SR, He W, Atkinson CL, Smith JJ, Liu Z, et al. (2011) Mitochondrialnuclear communication by prohibitin shuttling under oxidative stress. Biochemistry 50: 8342-8351.

31. Varadarajan S, Butterworth $M$, Wei J, Pellecchia M, Dinsdale D, et al. (2013) Sabutoclax (BI97C1) and BI112D, putative inhibitors of MCL-, induce mitochondrial fragmentation either upstream of or independent of apoptosis. Neoplasia 15: 568-578.

32. Jebahi A, Villedieu M, Pétigny-Lechartier C, Brotin E, Louis MH, et al. (2014) $\mathrm{PI} 3 \mathrm{~K} / \mathrm{mTOR}$ dual inhibitor NVP-BEZ235 decreases Mcl-1 expression and sensitizes ovarian carcinoma cells to $\mathrm{Bcl}-\mathrm{xL}$-targeting strategies, provided that Bim expression is induced. Cancer Lett 348: 38-49.

33. Kim HS, Kim TJ, Chung HH, Kim JW, Kim BG, et al. (2009) In vitro extreme drug resistance assay to taxanes or platinum compounds for the prediction of clinical outcomes in epithelial ovarian cancer: a prospective cohort study. J Cancer Res Clin Oncol 135: 1513-1520.

34. Lee HJ, Kim HS, Park NH, Chung HH, Kim JW, et al. (2013) Feasibility of Oxaliplatin, Leucovorin, and 5-Fluorouracil (FOLFOX-4) Chemotherapy in Heavily Pretreated Patients with Recurrent Epithelial Ovarian Cancer. Cancer Res Treat 45: 40-47.

35. Cancer Genome Atlas Research Network (2011) Integrated genomic analyses of ovarian carcinoma. Nature 474: 609-615.

36. Weberpals JI, Koti M, Squire JA (2011) Targeting genetic and epigenetic alterations in the treatment of serous ovarian cancer. Cancer Genet 204: 525535

37. Liu MX, Siu MK, Liu SS, Yam JW, Ngan HY, et al. (2014) Epigenetic silencing of microRNA-199b-5p is associated with acquired chemoresistance via activation of JAG1-Notch1 signaling in ovarian cancer. Oncotarget 5: 944-958.

38. Munksgaard PS, Blaakaer J (2012) The association between endometriosis and ovarian cancer: a review of histological, genetic and molecular alterations. Gynecol Oncol 124: 164-169.

39. Bensaad K, Tsuruta A, Selak MA, Vidal MN, Nakano K, et al. (2006) TIGAR, a p53-inducible regulator of glycolysis and apoptosis. Cell 126: 107-120.

40. Suzuki S, Tanaka T, Poyurovsky MV, Nagano H, Mayama T, et al. (2010)
Phosphate-activated glutaminase (GLS2), a p53-inducible regulator of glutamine metabolism and reactive oxygen species. Proc Natl Acad Sci U S A 107: 7461-7466.

41. Matoba S, Kang JG, Patino WD, Wragg A, Boehm M, et al. (2006) p53 regulates mitochondrial respiration. Science 312: 1650-1653.

42. Kawauchi K, Araki K, Tobiume K, Tanaka N (2008) p53 regulates glucose metabolism through an IKK-NF-kappaB pathway and inhibits cell transformation. Nat Cell Biol 10: 611-618.

43. Hu W, Zhang C, Wu R, Sun Y, Levine A, et al. (2010) Glutaminase 2, a novel p53 target gene regulating energy metabolism and antioxidant function. Proc Natl Acad Sci U S A 107: 7455-7460.

44. Goldstein I, Ezra O, Rivlin N, Molchadsky A, Madar S, et al. (2012) p53, a nove regulator of lipid metabolism pathways. J Hepatol 56: 656-662.

45. Hu J, Liu Z, Wang X (2013) Does TP53 mutation promote ovarian cance metastasis to omentum by regulating lipid metabolism? Med Hypotheses 81 : 515-520.

46. Barthel A, Okino ST, Liao J, Nakatani K, Li J, et al. (1999) Regulation of GLUT1 gene transcription by the serine/threonine kinase Akt1. J Biol Chem 274 20281-20286

47. Vander Heiden MG, Plas DR, Rathmell JC, Fox CJ, Harris MH, et al. (2001) Growth factors can influence cell growth and survival through effects on glucose metabolism. Mol Cell Biol 21: 5899-5912.

48. Lunt SY, Vander Heiden MG (2011) Aerobic glycolysis: meeting the metabolic requirements of cell proliferation. Annu Rev Cell Dev Biol 27: 441-464.

49. Yun J, Rago C, Cheong I, Pagliarini R, Angenendt P, et al. (2009) Glucose deprivation contributes to the development of KRAS pathway mutations in tumor cells. Science 325: 1555-1559.

50. Cecconi S, Mauro A, Cellini V, Patacchiola F (2012) The role of Akt signalling in the mammalian ovary. Int J Dev Biol 56: 809-817.

51. Hers I, Vincent EE, Tavaré JM (2011) Akt signalling in health and disease. Cell Signal 23: 1515-1527.

52. Pennington K, Pulaski H, Pennington M, Liu JR (2010) Too much of a good thing: suicide prevention promotes chemoresistance in ovarian carcinoma. Curr Cancer Drug Targets 10: 575-583.

53. Wang Y, Dong L, Cui H, Shen DH, Wang Y, et al. (2011) Up-regulation of mitochondrial antioxidation signals in ovarian cancer cells with aggressive biologic behavior. J Zhejiang Univ Sci B 12: 346-356.

54. Kunej T, Wang Z, Michal JJ, Daniels TF, Magnuson NS, et al. (2007) Functional UQCRC1 polymorphisms affect promoter activity and body lipid accumulation. Obesity (Silver Spring) 15: 2896-2901.

55. Sotgia F, Martinez-Outschoorn UE, Lisanti MP (2013) Cancer metabolism: new validated targets for drug discovery. Oncotarget 4: 1309-1316.

56. Lim HY, Ho QS, Low J, Choolani M, Wong KP (2011) Respiratory competent mitochondria in human ovarian and peritoneal cancer. Mitochondrion 11: 437 443.

57. Permuth-Wey J, Chen YA, Tsai YY, Chen Z, Qu X, et al. (2011) Inherited variants in mitochondrial biogenesis genes may influence epithelial ovarian cancer risk. Cancer Epidemiol Biomarkers Prev 20: 1131-1145.

58. Liu VW, Shi HH, Cheung AN, Chiu PM, Leung TW, et al. (2001) High incidence of somatic mitochondrial DNA mutations in human ovarian carcinomas. Cancer Res 61: 5998-6001.

59. Kurita T, Izumi H, Kagami S, Kawagoe T, Toki N, et al. (2012) Mitochondrial transcription factor A regulates BCL2L1 gene expression and is a prognostic factor in serous ovarian cancer. Cancer Sci 103: 239-444.

60. Boland ML, Chourasia AH, Macleod KF (2013) Mitochondrial dysfunction in cancer. Front Oncol 3: 292.

61. Sena LA, Chandel NS (2012) Physiological roles of mitochondrial reactive oxygen species. Mol Cell 48: 158-167.

62. Bensinger SJ, Christofk HR (2012) New aspects of the Warburg effect in cancer cell biology. Semin Cell Dev Biol 23: 352-361.

63. Pavlides S, Whitaker-Menezes D, Castello-Cros R, Flomenberg N, Witkiewicz AK, et al. (2009) The reverse Warburg effect: aerobic glycolysis in cancer associated fibroblasts and the tumor stroma. Cell Cycle 8: 3984-4001. 
Citation: Uddin MH, Kim B, Suh DH, Song YS (2014) Anticancer Strategy Targeting Mitochondrial Biogenesis in Ovarian Cancer. J Cancer Sci Ther 6: 422-428. doi:10.4172/1948-5956.1000303

64. Koppenol WH, Bounds PL, Dang CV (2011) Otto Warburg's contributions to current concepts of cancer metabolism. Nat Rev Cancer 11: 325-337.

65. Jang M, Kim SS, Lee J (2013) Cancer cell metabolism: implications for therapeutic targets. Exp Mol Med 45: e45.

66. Martinez-Outschoorn UE, Pavlides S, Howell A, Pestell RG, Tanowitz HB, et al. (2011) Stromal-epithelial metabolic coupling in cancer: integrating autophagy and metabolism in the tumor microenvironment. Int $\mathrm{J}$ Biochem Cell Biol 43: 1045-1051.

67. Martinez-Outschoorn UE, Sotgia F, Lisanti MP (2012) Power surge: supporting cells "fuel" cancer cell mitochondria. Cell Metab 15: 4-5.

68. Isonishi S, Saitou M, Yasuda M, Tanaka T (2001) Mitochondria in platinum resistant cells. Hum Cell 14: 203-210.

69. Hallberg BM, Larsson NG (2011) TFAM forces mtDNA to make a U-turn. Nat Struct Mol Biol 18: 1179-1181.

70. Lu B, Lee J, Nie X, Li M, Morozov YI, et al. (2013) Phosphorylation of human TFAM in mitochondria impairs DNA binding and promotes degradation by the AAA+ Lon protease. Mol Cell 49: 121-132.

71. Lee $\mathrm{CH}$, Wu SB, Hong $\mathrm{CH}$, Liao WT, Wu CY, et al. (2011) Aberrant cell proliferation by enhanced mitochondrial biogenesis via mtTFA in arsenical skin cancers. Am J Pathol 178: 2066-2076.

72. Yao J, Zhou E, Wang Y, Xu F, Zhang D, et al. (2014) microRNA-200a inhibits cell proliferation by targeting mitochondrial transcription factor $\mathrm{A}$ in breas cancer. DNA Cell Biol 33: 291-300.

73. Mo M, Peng F, Wang L, Peng L, Lan G, et al. (2013) Roles of mitochondrial transcription factor $A$ and microRNA-590-3p in the development of bladder cancer. Oncol Lett 6: 617-623.

74. Ivanova MM, Radde BN, Son J, Mehta FF, Chung SH, et al. (2013) Estradio and tamoxifen regulate NRF-1 and mitochondrial function in mouse mammary gland and uterus. J Mol Endocrinol 51: 233-246.

75. Kim AJ, Jee HJ, Song N, Kim M, Jeong SY, et al. (2013) p21(WAF $\left.{ }^{1 / C^{1}} \mathrm{P}^{1}\right)$ deficiency induces mitochondrial dysfunction in HCT116 colon cancer cells. Biochem Biophys Res Commun 430: 653-658.

76. Jeong SH, Song IS, Kim HK, Lee SR, Song S, et al. (2012) An analogue of resveratrol HS-1793 exhibits anticancer activity against MCF-7 cells via inhibition of mitochondrial biogenesis gene expression. Mol Cells 34: 357-365.

77. Guo J, Zheng L, Liu W, Wang X, Wang Z, et al. (2011) Frequent truncating mutation of TFAM induces mitochondrial DNA depletion and apoptotic resistance in microsatellite-unstable colorectal cancer. Cancer Res 71: 29782987

78. Chowdhury I, Garcia-Barrio M, Harp D, Thomas K, Matthews R, et al. (2012) The emerging roles of prohibitins in folliculogenesis. Front Biosci (Elite Ed) 4: 690-699.

79. Schleicher M, Shepherd BR, Suarez Y, Fernandez-Hernando C, Yu J, et al. (2008) Prohibitin-1 maintains the angiogenic capacity of endothelial cells by regulating mitochondrial function and senescence. J Cell Biol 180: 101-112.

80. Tsutsumi T, Matsuda M, Aizaki H, Moriya K, Miyoshi H, et al. (2009) Proteomics analysis of mitochondrial proteins reveals overexpression of a mitochondrial protein chaperon, prohibitin, in cells expressing hepatitis $C$ virus core protein Hepatology 50: 378-386

81. Yuan Z, Cao K, Lin C, Li L, Liu HY, et al. (2011) The p53 upregulated modulator of apoptosis (PUMA) chemosensitizes intrinsically resistant ovarian cance cells to cisplatin by lowering the threshold set by $\mathrm{Bcl}-\mathrm{x}(\mathrm{L})$ and $\mathrm{Mcl}-1$. Mol Med 17: $1262-1274$.

82. Venticinque L, Meruelo $D$ (2010) Sindbis viral vector induced apoptosis requires translational inhibition and signaling through Mcl-1 and Bak. Mol Cancer 9: 37.

83. Roy G, Horton JK, Roy R, Denning T, Mitra S, et al. (2000) Acquired alkylating drug resistance of a human ovarian carcinoma cell line is unaffected by altered levels of pro- and anti-apoptotic proteins. Oncogene 19: 141-150.

84. Singh RK, Lange TS, Kim KK, Brard L (2011) A coumarin derivative (RKS262) inhibits cell-cycle progression, causes pro-apoptotic signaling and cytotoxicity in ovarian cancer cells. Invest New Drugs 29: 63-72.

85. Li H, Chen Y, Jones AF, Sanger RH, Collis LP, et al. (2008) Bcl-xL induces Drp1-dependent synapse formation in cultured hippocampal neurons. Proc Natl Acad Sci U S A 105: 2169-2174.

86. Maurer U, Charvet C, Wagman AS, Dejardin E, Green DR (2006) Glycogen synthase kinase- 3 regulates mitochondrial outer membrane permeabilization and apoptosis by destabilization of MCL-1. Mol Cell 21: 749-760.

87. Hatle KM, Neveu W, Dienz O, Rymarchyk S, Barrantes R, et al. (2007) Methylation-controlled J protein promotes c-Jun degradation to prevent ABCB1 transporter expression. Mol Cell Biol 27: 2952-2966.

88. Shridhar V, Bible KC, Staub J, Avula R, Lee YK, et al. (2001) Loss of expression of a new member of the DNAJ protein family confers resistance to chemotherapeutic agents used in the treatment of ovarian cancer. Cancer Res 61: 4258-4265.

89. Bristow N, Burton TR, Henson ES, Ong-Justiniano C, Brown M, et al. (2011) Truncated forms of BNIP3 act as dominant negatives inhibiting hypoxiainduced cell death. Biochim Biophys Acta 1812: 302-311.

90. Lai J, Flanagan J, Phillips WA, Chenevix-Trench G, Arnold J (2003) Analysis of the candidate 8 p21 tumour suppressor, BNIP3L, in breast and ovarian cancer. Br J Cancer 88: 270-276.

91. Glick D, Zhang W, Beaton M, Marsboom G, Gruber M, et al. (2012) BNip3 regulates mitochondrial function and lipid metabolism in the liver. Mol Cell Biol 32: $2570-2584$.

92. Lam SS, Mak AS, Yam JW2, Cheung AN2, Ngan HY3, et al. (2014) Targeting estrogen-related receptor alpha inhibits epithelial-to-mesenchymal transition and stem cell properties of ovarian cancer cells. Mol Ther 22: 743-751.

93. Wu F, Wang J, Wang Y, Kwok TT, Kong SK, et al. (2009) Estrogen-related receptor alpha (ERRalpha) inverse agonist XCT-790 induces cell death in chemotherapeutic resistant cancer cells. Chem Biol Interact 181: 236-242.

94. Sun P, Sehouli J, Denkert C, Mustea A, Könsgen D, et al. (2005) Expression of estrogen receptor-related receptors, a subfamily of orphan nuclear receptors, as new tumor biomarkers in ovarian cancer cells. J Mol Med (Berl) 83: 457-467.

95. Kathiria AS, Butcher LD, Feagins LA, Souza RF, Boland CR, et al. (2012) Prohibitin 1 modulates mitochondrial stress-related autophagy in human colonic epithelial cells. PLoS One 7: e31231.
Volume $6(10) 422-428(2014)-428$ 